\title{
Alveolar-arterial gradient and risk of hypoxemia in morbidly obese patients the day after laparoscopic bypass surgery: sustained effect of Boussignac CPAP?
}

Guimarães J, Pinho D, Cavaleiro C, Nunes C, Machado H

Serviço de Anestesiologia, Centro Hospitalar do Porto, Portugal

\section{BACKGROUND AND GOAL OF STUDY}

Morbidly obese patients develop more atelectasis during anesthesia which frequently persist twenty four hours after surgery. There's an increased risk of desaturation in this period.

Our purpose: to evaluate the impact of immediate post extubation use of Boussignac Continuous Positive Airway Pressure (CPAP) on alveolar-arterial gradient ( $A$-a gradient) and the prevalence of post-operative hypoxemia $(\mathrm{PaO} 2<60 \mathrm{mmHg}) 24 \mathrm{~h}$ after Roux-en- $\mathrm{Y}$ laparoscopic gastric bypass.

\section{MATERIALS AND MethodS}

\section{- Prospective study}

- Health Ethics Committee Approval; Written informed consent.

- Inclusion criteria: body mass index $>35 \mathrm{Kg} / \mathrm{m}^{2}$, age $18-65$ years, ASA 1-3.

- Exclusion criteria: preexisting lung parenchyma disease, chronic obstructive pulmonary disease, moderate to severe asthma, congestive heart failure (NYHA>II), $[\mathrm{Hb}]<7 \mathrm{~g} / \mathrm{dl}$ or if there were language barriers or severe psychiatric disorder.

- The same anesthetic and analgesic protocols.

- Attending anaesthesiologist blinded to the study groups until the end of surgery.

- Patients randomly assigned to receive Boussignac CPAP or venturi mask immediately after extubation in the operating room. Intervention for 2 hours in recovery room.

- Blood gas analysis (PaO2, A-a gradient): preoperative period - T0 (FiO2 0.21), 1h - T1 (FiO2 0.5) and 24h - T24 (FiO2 0.21) after extubation.

- Statistics: student's t and chi-squared tests. $p$-value $<0.05$

\section{RESULTS}

- 11 patients in each group.

- No differences in demographic and preoperative data (Tables 1 and 2)

\begin{tabular}{|l|c|c|}
\hline \multicolumn{1}{|c|}{ Variables } & Boussignac group & Venturi group \\
\hline Age (years) & $41.82 \pm 6.98$ & $44.75 \pm 12.28$ \\
\hline Gender (M/F) & $1 / 10$ & $2 / 9$ \\
\hline BMI $\left(\mathrm{Kg} / \mathrm{m}^{2}\right)$ & $43.35 \pm 5.56$ & $43.49 \pm 6.49$ \\
\hline ASA classification $(2 / 3)$ & $10 / 1$ & $11 / 0$ \\
\hline
\end{tabular}

TABLE 1 - Patients baseline characteristics

\begin{tabular}{|c|c|c|c|c|}
\hline & Variables & Boussignac group & Venturi group & $p$ value \\
\hline \multirow{3}{*}{ TO } & $\mathrm{PaO} 2<60 \mathrm{mmHg}$ & $0(0)$ & $0(0)$ & \\
\hline & $\mathrm{PaO2}$ & $86.62 \pm 13.43$ & $82.64 \pm 16.45$ & $>0.05$ \\
\hline & A-a Gradient & $26.06 \pm 10.02$ & $27.13 \pm 13.53$ & $>0.05$ \\
\hline \multirow{3}{*}{ T1 } & $\mathrm{PaO} 2<60 \mathrm{mmHg}$ & $0(0)$ & $0(0)$ & \\
\hline & $\mathrm{PaO2}$ & $149.75 \pm 62.71$ & $91.98 \pm 25.76$ & 0.014 \\
\hline & A-a Gradient & $148.96 \pm 75.98$ & $211.42 \pm 18.05$ & 0.04 \\
\hline \multirow{3}{*}{ T24 } & $\mathrm{PaO} 2<60 \mathrm{mmHg}$ & $0(0)$ & $4(36)$ & \\
\hline & $\mathrm{PaO2}$ & $79.64 \pm 9.18$ & $64.88 \pm 6.05$ & $<0.001$ \\
\hline & A-a Gradient & $27.79 \pm 7.93$ & $37.67 \pm 6.45$ & 0.006 \\
\hline
\end{tabular}

Data are presented as frequency (percentage) or mean $\pm \mathrm{SD}$

TABLE 2 - Perioperative data

- No PaO2 values $<60 \mathrm{mmHg}$ at T0 and T1 in both groups. At T24 no patient in the Boussignac group and $36 \%$ of patients in the venturi group had a $\mathrm{PaO} 2<60 \mathrm{mmHg}$.

- After extubation A-a gradient was significantly lower in the Boussignac group at T1 and T24.

\section{Discussion}

In line with our study results it seems that Venturi group patients are more prone to have hypoxemia.

A lower A-a gradient after extubation in the Boussignac group may be an indicator of a better ventilation/perfusion matching and suggests a positive effect of CPAP in the prevention of additional atelectasias after surgery. 